\title{
PENERAPAN MODEL KONTEKSTUAL BERBANTUAN MULTIMEDIA UNTUK MENINGKATKAN PENGUASAAN KONSEP DAN LITERASI SAINS SISWA PADA MATERI FLUIDA DI SMA KELAS XI IPA
}

\author{
Heri Sugianto \\ Kepala Sekolah SMPIT As-Syifa Subang \\ email: faihasatu@gmail.com
}

\begin{abstract}
ABSTRAK
Penelitian ini bertujuan untuk mengetahui peningkatan penguasaan konsep dan kemampuan literasi sains siswa dengan menggunakan model pembelajaran kontekstual berbantuan multimedia.Metode dan desain penelitian yang digunakan adalah quasi experiment dengan pretest-posttest control group design. Subjek penelitiannya adalah kelas XI di kabupaten Subang, Jawa-Barat.H asil penelitian menunjukkan Model Pembelajaran Kontekstual berbantuan multimedia secara signifikan mampu meningkatkan penguasaan konsep dan kemampuan literasi sains siswa. Peningkatan penguasaan konsep siswa dengan nilai N-Gain 0.50 (kategori sedang) untuk kelas eksperimen dan 0,30 (kategori sedang) untuk kelas kontrol. Peningkatan kemampuan literasi sains siswa dengan nilai N-Gain 0.45 (kategori sedang) untuk kelas eksperimen dan 0,30 (kategori sedang) untuk kelas kontrol.
\end{abstract}

Kata kunci: model pembelajaran kontekstual, multimedia, penguasaan konsep dan kemampuan literasi sains

\section{ABSTRACT}

This studyaims to determine the conceptsmastery and skills in creasescientific literacyof students byusing multi media-assisted contextuallearning model. The method used quasi experiment with pretest-posttest control group design. Subjects of study are class XI in Subang districts, West-Java. The result of study showed that contextual model's aided by multi media significantly enhance student's concepts mastery and skills scientific literacy.The enhancement of student'sconcepts mastery with $N$-Gain value is 0.50 (medium category) for experimentclass and 0,30 (medium category) for controlclass. The enhancement of student'sskills scientific literacy with $N$-Gain value is 0.45 (medium category) for experiment class and 0,30 (medium category) for controlclass.

Keywords: contextual model's, Multimedia, concept mastery and skill scientific literacy

\section{PENDAHULUAN}

Mata pelajaran Fisika yang merupakan bagian dari IPA berfungsi untuk mengembangkan kemampuan berpikir analitis induktif dan deduktif dalam menyelesaikan masalah yang berkaitan dengan peristiwa alam, baik secara kualitatif maupun kuantitatif, serta dapat mengembangkan keterampilan dan sikap percaya diri.

Kenyataan di lapangan, proses pembelajaran Fisika dirasa masih jauh dari apa yang diharapkan. Dari pengamatan langsung peneliti di salah satu SMA di kabupaten Subang diperoleh bahwa sebagian besar proses pembelajaran Fisika dilaksanakan dengan menggunakan pembelajaran satu arah yang lebih menekankan pada penyampaian materi pembelajaran (metode konvensional). sebernarnya sekolah mempunyai target dalam kurikulum mata pelajaran fisika, bagaimana siswa mempunyai kemampuan atau keterampilan sains yang dapat diaplikasikan dalam kehidupan sehari-hari.

Pada metode konvensional keterlibatan siswa secara aktif dalam proses belajar mengajar masih kurang. Proses belajar mengajar terpusat pada guru, sehingga siswa menerima pelajaran secara pasif. Tidak mengherankan apabila konsep yang telah tertanam tidak akan bertahan lama dan akan mudah hilang lagi. Kelemahan lain dalam penggunaan metode konvensional adalah pengajarannya yang terlampau matematis. Menurut Sumarna (2004) kebanyakan peserta didik mengalami kesulitan dalam mengaplikasikan pengetahuan dalam kehidupan nyata (real 
world). Zamroni (2000) menyatakan, hal di atas disebabkan adanya kecenderungan pembelajaran di kelas yang tidak berusaha mengaitkan konten pelajaran dengan kehidupan sehari-hari. Pernyataan senada disampaikan Conny Semiawan (2000) bahwa pembelajaran lebih banyak memaparkan fakta, pengetahuan, dan hukum, kemudian biasa dihafalkan, bukan mengaitkannya dengan pengalaman empiris dalam kehidupan nyata. Siswa cenderung dituntut untuk menghapal rumus dan penggunaan rumus tersebut tanpa memahami konsep-konsep yang melatar belakangi terbentuknya rumus tersebut, sehingga siswa pun sulit menyerap konsep-konsep fisisnya. Hal ini berdampak pada rendahnya hasil penguasaan konsep fisika yang dicapai siswa. Seperti ditunjukan pada nilai rata-rata akhir semester gasal 5,00 dan ulangan harian untuk materi sebelumnya 5,40 .

Kajian pustaka; Salah satu Model pembelajaran yang dibangun dengan prinsipprinsip di atas, dan concern terhadap upayaupaya implementasi dalam kehidupan nyata adalah Model pembelajaran kontekstual (contextual teaching and learning [CTL]). Pembelajaran kontekstual adalah pembelajaran yang berusaha mengaitkan konten mata pelajaran dengan situasi dunia nyata dan memotivasi siswa menghubungkan pengetahuan yang dimiliki dengan kehidupan mereka sehari-hari (Blancard, 2001 dan Johnson, 2002). Untuk mewujudkan pembelajaran yang memiliki karakteristik seperti di atas, proses pembelajaran harus menekankan pada: making meaningful connection, constructivism, inquiry, critical and creative thinking, learning community, dan using authentic assessment.

Menurut University of Washington, beberapa strategi pembelajaran berikut ini menempatkan siswa dalam konteks sesuai CTL. Pembelajaran autentik, yakni pembelajaran yang memungkinkan siswa belajar dalam konteks sebenarnya, yaitu kehidupannya sehari-hari (daily lives). Pembelajaran berbasis inkuiri, yakni strategi pembelajaran yang berpola pada metode ilmiah, observasi dilakukan, masalah ditemukan, dirumuskan hipotesis, kemudian hipotesis diuji dengan eksperimen, sehingga diperoleh kesimpulan. Pembelajaran berbasis masalah, yakni pembelajaran yang menggunakan masalah-masalah dunia nyata (real-world) sebagai konteks bagi siswa untuk berpikir kritis dan melatih keterampilan problem solving.

Arah pembelajaran memasuki millennium ketiga memadukan unsur-unsur teknologi komunikasi, aspek audio, visual dan grafis dalam bentuk multimedia yang dapat diakses secara online kapan dan dimana saja. Luasnya kajian tentang multimedia dalam pendidikan, maka tulisan ini difokuskan pada pembelajaran berbasis computer yang juga mengacu pada hal yang terkait dengan ICT, sebagai perangkat multimedia. Dalam tulisan ini akan dibahas secara garis besar bagaimana pemanfaatan perangkat multimedia dalam pembelajaran. Menurut beberapa penelitian diantaranya yang di ungkapkan Wiendartun, Taufik dan Hery (2007) mengungkapkan bahwa, pembelajaran berbasis multimedia dapat meningkatkan hasil belajar siswa. Sedangkan hasil penelitian Selahattin (2006) menunjukkan bahwa komputer dan kontruktivis sama-sama dapat meningkatkan pemahaman.

Berdasarkan pemaparan di atas, maka penulis memandang perlu untuk melakukan sebuah penelitian mengenai penerapan model pembelajaran contextual teaching and learning (CTL) berbantuan multimedia untuk meningkatkan penguasaan konsep dan literasi sains siswa pada pokok bahasan fluida statis.

Rumusan mesalah penelitian ini adalah: Berdasarkan latar belakang masalah yang telah diuraikan di atas, maka permasalahan dalam penelitian ini dapat dirumuskan dalam 
bentuk pertanyaan sebagai berikut: "apakah model pembelajaran Contextual Teaching And Learning(CTL) berbantuan multimedia dapat lebih meningkatkan penguasaan konsep, dan kemampuan literasi sains siswa dibandingkan pembelajaran konvensional berbantuan multimedia?". Untuk lebih mengarahkan penelitian, maka rumusan masalah di atas dijabarkan menjadi beberapa pertanyaan penelitian sebagai berikut: (1). Bagaimanakah peningkatan kemampuan penguasaan konsepsiswa antara yang mendapatkan model kontekstual berbantuan multimedia dibandingkan dengan yang mendapatkan pembelajaran konvensional berbantuan multimedia?, (2). Bagaimanakah peningkatan kemampuan literasi sains siswa antara yang mendapatkan model kontekstual berbantuan multimedia dibandingkan dengan yang mendapatkan pembelajaran konvensional berbantuan multimedia?

Penelitian ini bertujuan untukmengetahui peningkatan penguasaan konsep siswa pada materi fluida statis pada kelas yang menggunakan Model Kontekstual berbantuan multimedia dibandingkan dengan kelas yang menggunakan pembelajaran konvensional berbantuan multimedia dan untuk mengetahui peningkatan kemampuan literasi sainssiswa pada materi fluida statis pada kelas yang menggunakan Model Kontekstual berbantuan multimedia dibandingkan dengan kelas yang menggunakan pembelajaran konvensional berbantuan multimedia.

\section{METODE PENELITIAN}

Penelitian ini bertujuan untuk menguji peningkatan penerapan model kontekstual berbantual multimedia dalam pembelajaran fisika terhadap penguasaan konsep dan kemamapuan literasi sains, sehingga metode yang digunakan dalam penelitian ini adalah metode quasi eksperiment dengan desain "control group pretest-posttest design" (Fraenkel, 2007). Desain ditunjukkan pada Tabel 1.

Tabel 1

Design Penelitian

\begin{tabular}{cccc}
\hline Kelas & Pretest & Perlakuan & Postest \\
\hline Eksperimen & $\mathrm{O}_{1}$ & $\mathrm{X}_{1}$ & $\mathrm{O}_{2}$ \\
\hline Kontrol & $\mathrm{O}_{1}$ & $\mathrm{X}_{2}$ & \\
\hline Keterangan: & & \\
$\mathrm{X}_{1}=$ & Model pembelajaran kontekstual berbantuan mutimedia & \\
$\mathrm{X}_{2}=$ & Model pembelajaran konvensional berbantual multimedia & \\
$\mathrm{O}_{1}=$ & tes awal dan tes akhir kemampuan kognitif & \\
$\mathrm{O}_{2}=$ & tes akhir gaya berpikir kreatif-kritis &
\end{tabular}

Populasi penelitian ini adalah siswa kelas XI di SMA semester dua tahun pelajaran 2012/2013 di kabupaten Subang. Sampel penelitian terdiri atas dua kelas penelitian, masing-masing sebagai kelas eksperimen dan kelas kontrol yang dipilih secara cluster-random sampling. Kelas eksperimen berjumlah 20 orang siswa dan kelas kontrol berjumlah 20 orang siswa.

Data dalam penelitian ini dikumpulkan di awal pembelajaran, selama proses pembelajaran dan di akhir pembelajaran dengan menggunakan dua macam cara pengumpulan data yaitu melalui tes dan observasi. Instrumen tes penguasaan konsep dan kemampuan literasi sains terlebih dahulu di judgmen oleh ahli dan di uji coba di kelas XII serta dianalisis untukmengetahui kelayakan instrumen yang digunakan yang meliputi perhitungan Validitas Instrumen, Reliabilitas Instrumen, Tingkat Kesukaran, dan Daya Pembeda Butir Soal.

Analisis data yang dimaksudkan untuk membuat penafsiran data yang diperoleh dari hasil penelitian. Analisis data tersebut digunakan untuk mengetahui peningkatan penguasaan konsep dan kemampuan literasi sains serta keterlaksanaan model pembelajaran kontekstual berbantuan multimedia. Data yang diperoleh dari 
observasi dianalisis secara deskriptif untuk mengetahui keterlaksanaan model dalam pembelajaran. Data peningkatan penguasaan konsepdankemampuan literasi sains dianalisis dengan uji statistik. Dalam penelitian ini analisis data statistik menggunakan program SPSS for Windows versi 16.0.Analisis Peningkatan penguasaan konsep dan kemampuan literasi sainssebagai berikut: (a) Penskoran; (b) Menghitung ratarata (mean) skor pretest dan posttest; dan (c) Menghitung Gain skor pretest dan posttest

Peningkatan yang terjadi sebelum dan sesudah pembelajaran dihitung dengan gain yang dinormalisasi dengan rumus maltzer (dalam oktavien 2012):
a. Uji statistik

$$
\text { Normalized gain }=\frac{\text { posttest score }- \text { pretestt score }}{\text { maximum possible score }- \text { pretest score }}
$$

Tabel 2

Klasifikasi Gain Ternormalisasi

\begin{tabular}{cc}
\hline Besarnya N-gain $(\mathrm{g})$ & Klasifikasi \\
\hline $\mathrm{g} \geq 0,70$ & Tinggi \\
\hline $0,30 \leq \mathrm{g}<0,70$ & Sedang \\
\hline $\mathrm{g}<0,30$ & Rendah \\
\hline
\end{tabular}

(Meltzer (dalam Oktavien, 2012)

Analisis keterlaksanaan model pembelajaran yang disajikan dilakukan oleh observer dengan melakukan observasi selama pembelajaran, yang dianalisis dengan menggunakan persentase. Untuk menguji tingkat signifikansi perbedaan rerata peningkatan penguasaan konsep dan kemampuan literasi sainsdilakukan dengan analisis secara statistik. Pengujian hipotesis dalam penelitian ini menggunakan uji Mann-Whitney $U$ dua ekor (2-tailed) dengan taraf signifikan $\alpha=0,05$ dan uji-t dua ekor (2-tailed) dengan taraf signifikan $\alpha=0,05$.

\section{HASIL DAN PEMBAHASAN}

1. Keterlaksanaan Model Kontekstual Berbantuan Multimedia

Data keterlaksanaan model diperoleh melalui pengamatan yang dilakukan oleh observer dengan pengolahan data menggunakan bantuan program Microsoft Office Excel 2010. Berikut ini disajikan persentase keterlaksaan model pembelajaran yang dilakukan pada pertemuan satu dan pertemuan dua dalam bentuk Tabel 3.

Tabel 3

Keterlaksaan Model Pembelajaran

\begin{tabular}{lllll}
\hline No & Indikator keterlaksanaan model & $\begin{array}{c}\text { Pertemuan } \\
\text { I (\%) }\end{array}$ & $\begin{array}{c}\text { Pertemuan } \\
\text { II (\%) }\end{array}$ & Intepretasi \\
\hline$\frac{1}{2}$ & Konstruktivisme & 100 & 100 & $\frac{\text { Sangat Baik }}{\text { Sangat Baik }}$ \\
\hline$\frac{1}{3}$ & Bertanya & 100 & 100 & $\frac{\text { Sangat Baik }}{\text { Sangat Baik }}$ \\
\hline$\frac{1}{5}$ & Masyarakat Belajar & 100 & 100 & $\frac{\text { Sangat Baik }}{\text { Pemodelan }}$ \\
\hline 6 & Refleksi & 100 & 100 & Sangat Baik \\
\hline & 100 & 100 & Sangat Baik \\
\hline
\end{tabular}

Berdasarkan Tabel 3 di atas terlihat bahwa percentase rataan keterlaksaan model pembelajaran di kelas eksperimen pada kedua pertemuan adalah $100 \%$, sehingga dapat diintpretasikan keterlaksaan model pembelajaran dikelas eksperimen dengan dua kali pertemuan adalah sangat baik. 
2. Peningkatan penguasaan Konsep

Diagram persentase perbandingan skor rata-rata pre-test, post-test, dan gain yang dinormalisasi penguasaan konsep tentang konsep fluida statis antara kelas eksperimen dan kelas kontrol disajikan dalam diagram pada Gambar 1.

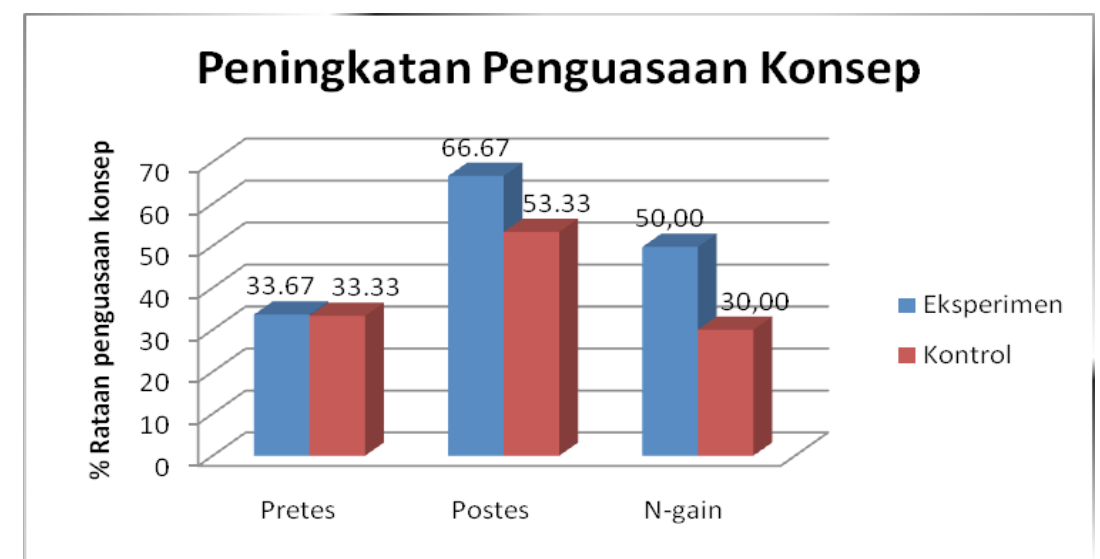

Gambar 1. Presentase Skor Rata-rata pre-test, post-test, dan Gain yang dinormalisasi penguasaan konsep Siswa pada Kedua Kelas

Peningkatan penguasaan konsep tentang konsep fluida statis siswa sebelum dan setelah pembelajaran sangat erat kaitannya dengan nilai $N$-gain (gain yang dinormalisasi). Skor rata-rata gain yang dinormalisasi kemampuan kognitif tentang konsep fluida statis siswa pada kelas eksperimen sebesar 0.50dengan kategori sedangdan pada kelas kontrol sebesar 0.30 dengan kategori sedang. Meskipun klasifikasi N-gain di kedua kelas bernilai sama, yaitu sedang, akan tetapi hasil ini menunjukkan bahwa peningkatan penguasaan konsep di kelas eksperimen lebih 0,20 dibandingkan di kelas kontrol. Adanya perbedaan tersebut dimungkinkan karena model pembelajaran kontekstual berbantuan multimedia memberikan kesempatan kepada siswa untuk belajar lebih leluasa dan mandiri, juga mampu membuat siswa untuk terlibat aktif dalam pembelajaran sehingga membuat kegiatan belajar lebih bermakna.

Berdasarkan hasil uji hipotesis diperoleh kesimpulan bahwa terdapat perbedaan peningkatan yang signifikan penguasaan konsep pada siswa yang mendapatkan model pembelajaran kontekstual berbantuan multimedia dibandingkan siswa yang mendapatkan pembelajaran konvensionalberbantuan multimedia. Hal ini menandakan bahwa penguasaan konsep siswa yang mendapatkan pembelajaran dengan model kontekstual berbantuan multimedia pada sampel terpilih berjalan sesuai dengan apa yang diharapkan. Peningkatan ini dengan menggunakan pembelajaran model kontekstual dipertegas oleh Wahyanti (2012) yang mengemukakan bahwa pembelajaran dengan menerapkan model Kontekstual dapat meningkatakan penguasaan konsep siswa. Hal senada juga dikemukakan oleh Nugraha (2010) yang menyatakan bahwa guru yang menerapkan model kontekstual dalam pembelajarannya dapat meningkatkan hasil belajar siswa.

Menurut Jabar (2011) model kontekstual juga mampu meningkatkan penguasaan konsep dengan rata-rata $\mathrm{N}$-gain ternormalisasi sebesar 0,62 . Mereka yakin tentang penyediaan bahan-bahan yang tepat, mempromosikan eksperimentasi, dan mulai mengkonstruksi pengetahuan anak, sehingga dengan model kontekstual bantuan multimedia ternyata mampu meningkatkan penguasaan konsep siswa.

3. Peningkatan Kemampuan Literasi Sains

Diagram persentase perbandingan skor rata-rata pre-test, post-test, dan gain yang dinormalisasi kemampuan literasi sains 
tentang konsep fluida statis antara kelas diagram pada Gambar 2.

eksperimen dan kelas kontrol disajikan dalam

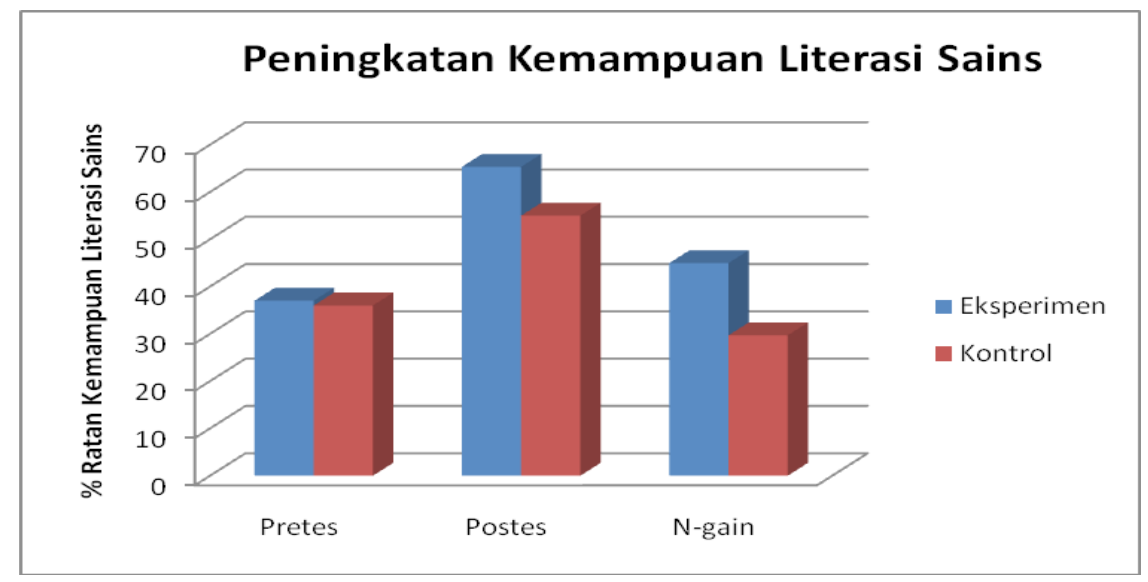

Gambar 2. Presentase Skor Rata-rata pre-test, post-test, dan Gain yang kemampuan literasis sains Siswa pada Kedua Kelas

Hasil analisis data pretes di kelas eksperimen dan kontrol diperoleh bahwa kemampuan literasi sians awal siswa di kedua kelas tidak terdapat perbedaan. Pembelajaran dengan model kontekstual untuk kelas eksperimen dan konvensional untuk kelas kontrol yang berlangsung selama dua pertemuan, serta diawali dengan pretes dan diakhiri dengan postes diperoleh hasil bahwa terdapat perbedaan kemampuan literasi sains pada kedua kelas tersebut dengan rataan postes 65,33 untuk kelas eksperimen dan 33,33 untuk kelas kontrol. Sedangkan untuk pencapaian kemampuan literasi sains siswa diperoleh hasil bahwa peningkatan kemampuan literasi di kelas eksperimen dengan kelas kontrol berbeda secara signifikan.

Jika dilihat dari analisis di atas, diperoleh nilai rataan $\mathrm{N}$-gain untuk kelas eksperimen adalah 0,45 , sementara rataan $\mathrm{N}$-gain untuk kelas kontrol adalah 0,30 dengan perbedaan rataan $\mathrm{N}$-gain sebesar 0,150. Meskipun klasifikasi $\mathrm{N}$-gain di kedua kelas bernilai sama, yaitu sedang, akan tetapi hasil ini menunjukkan bahwa peningkatan kemampuan literasi di kelas eksperimen lebih rendah 0,150 dibandingkan di kelas kontrol.

Faktor keberhasilan kembali penerimaan hipotesis yang menyatakan peningkatan kemampuan literasi sains siswa yang mendapatkan pembelajaran fisika dengan model kontekstual berbantuan multimedia lebih baik secara signifikan daripada siswa yang mendapat pembelajaran secara konvensional", Kesesuaian antara hipotesis yang dibuat dengan hasil yang diperoleh dimungkinkan karena model kontekstual berbantuan multimedia cocok digunakan di kelas tersebut yang dengan alasan:

Pertama, siswa dapat melaksanakan pembelajaran dengan menggunakan model kontekstual. Pembelajaran dilakukakan secara berkelompok dan pemberian bahan ajar dengan materi ke masing-masing siswa yang dilengkapi dengan bantuan multimedia cukup banyak membantu siswa untuk menguasai materi. Sebagian besar siswa melakukan kegiatannya sendiri yang difasilitasi oleh guru. Hal ini menandakan bahwa penguasaan konsep siswa yang mendapatkan pembelajaran dengan model kontekstual berbantuan multimedia pada sampel terpilih berjalan sesuai dengan apa yang diharapkan. Peningkatan ini dengan menggunakan pembelajaran model kontekstual dipertegas oleh Wahyanti (2012) yang mengemukakan bahwa pembelajaran dengan menerapkan model Kontekstual dapat meningkatakan kemampuan literasi sains siswa. Hal senada juga dikemukakan oleh Nugraha (2010) yang menyatakan bahwa guru yang menerapkan model kontekstual 
dalam pembelajarannya dapat meningkatkan kemampuan literasi sains siswa. Mereka yakin tentang penyediaan bahan-bahan yang tepat, mempromosikan eksperimentasi, dan mulai mengkonstruksi pengetahuan anak, sehingga dengan model kontekstual bantuan multimedia ternyata mampu meningkatkan penguasaan konsep siswa.

\section{KESIMPULAN}

Berdasarkan data dan analisis hasil penelitian yang telah dilakukan tentang model pembelajaran kontekstual pada pembelajaran fluida statis untuk meningkatkan penguasaan konsep dan literasi sains dapat disimpulkan bahwa: (1) Model pembelajaran Kontekstual berbantuanmultimedia secara signifikandapat lebih meningkatkan penguasaan konsep siswa dibandingkan dengan model pembelajaran konvensional berbantuan multimedia dengan $\mathrm{N}$-gain 0,50 termasuk dalam kategori sedang; (2) Model pembelajaran Kontekstual berbantuan multimedia secara signifikan dapat lebih meningkatkan literasi sains siswa dibandingkan dengan model pembelajaran konvensional berbantuan multimedia dengan $\mathrm{N}$-gain 0,45 termasuk dalam kategori sedang.

\section{DAFTAR PUSTAKA}

Blancard, A. 2001. Contextual Teaching and Learning. B.E.S.T.

Conny, S. (1992), PendekatanKeterampilan Proses, Jakarta: Gramedia 1992), hal. 15.

Conny, S. 2000. “Relevansi Kurikulum Pendidikan Masa Depan” dalam Sindhunata (ed) Membuka Masa Depan Anak-anak Kita. Jogjakarta:Penerbit Kanisius, hlm. 19 - 31.

Johnson, E.B. 2002. Contextual Teaching and Learning. California: Corwin Press, Inc

Selahattin, G. K. dan Inan (2006). "the effect of the computer assistedteaching and 7e model of the constructivist learning methods on the achievements and attitudes of high school students". The Turkish Online Journal of Educational Technology.

Sumarna (2008). Hakikat Pembelajaran Kontekstual. Jakarta: Bumi Aksara.

Sumarna. S. 2004. "Peningkatan Pendidikan MIPA dalam Master Plan Pendidikan Indonesia 2005-2009". Makalah disampaikan dalam Seminar Nasional Penelitian, Pendidikan, dan Penerapan MIPA tanggal 2 Agustus 2004, kerjasama FMIPA UNY, Ditjen Dikti Depdiknas, dan IMSTEP-JICA.

Wiendartun, T. H. (2007). Pengaruh Pembelajaran Berbasis Multimedia Terhadap Hasil Belajar Fisika. Proceeding of The First International Seminar on Science Education. ISBN: 979-25-0599-7. Tidak diterbitkan.

Zamroni. 2000. Paradigma Pendidikan Masa Depan. Yogyakarta: Bigraf Publisi. 